\title{
Modeling Interdependence Using the Social Relations Model: The Investment Model in Family Relationships
}

\author{
Susan J. T. Branje \\ C. Finkenauer \\ W. H. J. Meeus \\ University of California, Davis
}

When studying family relationships, researchers often are interested in relational phenomena at an individual level, such as whether an individual child thrives in a particular family context; relational phenomena at the dyadic level, such as whether the mother is more committed than the father to the relationship; and relational phenomena at the familial level, such as whether some families are more satisfied with their relationships than other families. These three levels of relational phenomena, that is, individuals, dyadic relationships, and groups have to be distinguished and are reciprocally related within the family system (Hinde, 1997; Laursen \& Bukowski, 1997). However, their theoretical and methodological interdependence represents a challenge for empirical investigation. The family as a group includes the individual family members and relationships, but these parts combine in such a way that new structures emerge which have their own meaning and are more than a collection of its members and relationships and which may affect relationships and the relationship partners (Reis, Collins, \& Berscheid, 2000). Both statistical methods and theoretical frameworks are needed that allow us to disentangle the three levels and the influence they exert on each other and to capture the truly social nature of family relationships.

The interdependence of the three levels is apparent in family members' behavior toward other family members and their perceptions of other family 
members. These behaviors and perceptions simultaneously reflect a family member's individual characteristics, individual characteristics of the other family members, characteristics of the particular actor-partner relationship, and characteristics of the family as a system (Cook, 1994; Kashy \& Kenny, 1990). Thus, when people are asked to rate their family members, each rating comprises aspects of the rating person, his or her rated partner, their dyadic relationship, and the family in which they are embedded. A statistical and methodological tool to distinguish these aspects of ratings and thereby differentiate between different levels of influences is the Social Relations Model (SRM). This model was originally proposed by Kenny and La Voie (1984), and extended to the family context by Cook $(1993,1994)$ and Kashy and Kenny (1990).

This chapter aims to provide an overview of the unique and exciting possibilities that the SRM offers to researchers interested in the empirical investigation of family relationships. For a comprehensive understanding of theoretical and statistical interdependence, it begins by presenting a relational theory, specifically Rusbult's investment model (Rusbult, 1983) and applies it to the family. It will then highlight how the hypotheses that can be derived from the investment model translate into SRM. Subsequently, it will describe the SRM and its methodological requirements in more detail and illuminate the possibilities that SRM offers for family researchers. To illustrate some applications of the SRM, the chapter will present three applications of the SRM to findings on the investment model in families. Specifically, the chapter will first examine how the SRM allows us to disentangle and quantify the influence of the three different levels of relational phenomena in the investment model in families. Then, it will show how the SRM can be used to examine specific hypotheses and longitudinal relations in the investment model. Finally, the chapter will present one example of how the SRM can be used to examine individual outcomes by considering all levels of influence in a family over time. To this end, we will present our findings on how relational phenomena predict adolescent depression over time. The chapter will conclude by portraying some of the theoretical and practical implications of the use of SRM for theories and future research.

\section{A Theoretical Framework: The Investment Model}

According to the investment model (e.g., Rusbult, 1983), individuals are committed to their relationship to the extent that they are satisfied with the relationship. They are also more committed to the relationship if they have made investments in the relationship that may be lost if the relationship ends, and they are more committed to the relationship if they have poor alterna- 
tives to the relationship. Thus, relationship satisfaction and investments are positively related to relationship commitment, whereas quality of alternatives is negatively related to relationship commitment (Rusbult, 1983; Rusbult, Johnson, \& Morrow, 1986). The investment model has proved fruitful to explain processes in romantic and marital relationships. To explore the extent to which the investment model is applicable to explain commitment in family relationships, we used SRM. On a theoretical level family relationships are characterized by different levels of equality and voluntariness. In the following, we will first focus on the theoretical implications of these differences and consider their implications for SRM.

Differences in family relationships. Family relationships can be distinguished in terms of equality or whether they are horizontal or vertical. Although parent-child relationships may become more horizontal during adolescence, parent-child relationships can be regarded as more vertical and asymmetrical than marital relationships (e.g., Hartup, 1989; Maccoby, 1992; Russell, Pettit, \& Mize, 1998). Parent-child relationships are marked by unequal exchanges: Parents usually have more knowledge and social power than their children and are also expected to provide security and warmth for their children. Marital relationships are typically horizontal: They are characterized by equality, symmetry, mutual liking, and reciprocity between the marital partners (Laursen \& Bukowski, 1997). The horizontal versus vertical nature of different relationships in a family may affect the way the investment model explains relationship processes. Because of the vertical nature of their relationship with their children, parents may invest in their children independent of how satisfied they are with the relationship. In contrast, because of the horizontal nature of their relationship, marital partners may invest in their relationship to the extent to which they perceive their partner to invest in the relationship. Horizontal relationships are based more on mutuality and reciprocity than vertical relationships. Horizontal relationships, more than vertical relationships, need to be perceived as equitable to be satisfactory. Put differently, the benefits that one partner experiences in the relationship need to equal his or her costs or contributions to the relationship. Not only does the investment model differ across vertical and horizontal relationships, it is also likely to differ within vertical relationships. Specifically, while parents may invest in the relationship with their child independent of their satisfaction with the relationship, children's investment may well be contingent on their level of relationship satisfaction with their parents. Adolescents often make a point of being treated fairly by their parents and expect their parents 
to treat them like equal partners (Collins, Laursen, Mortensen, Luebker, \& Ferreira, 1997).

Another important difference between different types of relationships in a family is voluntariness. In involuntary relationships terminating the relationship is not an option. Marital relationships can be regarded as voluntary because marital partners have the possibility to divorce. This choice may be more difficult to make when there are children involved, but the choice is there. The relationship between parents and children can be regarded as involuntary. Parents and children are stuck to each other for better and worse. Parents and/or children may choose never to see each other again, for example, but they will always remain parents and children. Due to these differences in voluntariness across family relationships, quality of alternatives may not similarly apply to the parent-child relationship as to marital relationships. Further, parents are socially expected to invest in, take responsibility for, and care for their children. Parental investment also has an evolutionary basis and is directed at reproductive success (Kenrick, Sadalla, Groth, \& Trost, 1990). Therefore parents are likely to unconditionally invest in their children regardless of the costs of the relationship. This implies that satisfaction, investments, and quality of alternatives may be less related to commitment in parent-child relationships than in marital relationships. The SRM offers a unique opportunity to explore these suggestions and the investment model in families. Before presenting an empirical study, however, for comprehensive understanding of the SRM and its application to family relationships, we will first focus on SRM in more detail.

\section{The Social Relations Model in Three-Person Families}

To be able to use the SRM to examine family relationships, data must be collected within a round-robin design: Each participating family member has to rate the characteristics of each of the other family members, or evaluate his or her relationship with each of the other family members. In a threeperson family with two parents and one child, this means that data on six dyadic family relationships (three family members $\times$ two partners) are needed for a round-robin design. Family members have clearly assigned roles, such as mother, father, and adolescent. In family research, therefore, the different family members are not interchangeable. Because the individuals within families can be distinguished by their role, different effects for each of these roles can be estimated.

Within the SRM, each dyadic score can be disentangled into four different components: actor, partner, relationship, and family effects (see Figure 12.1). As an example, consider the father's commitment to his adolescent child. 

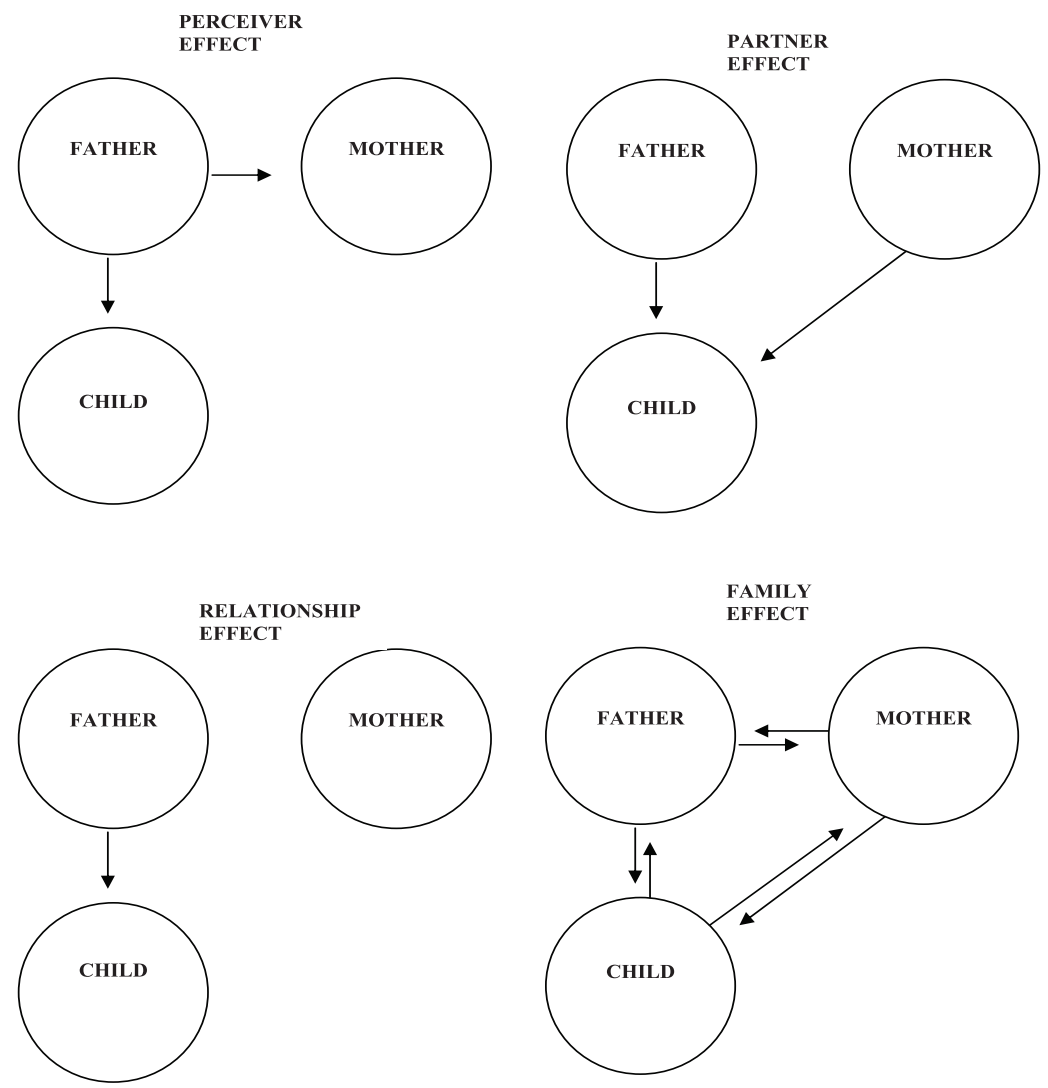

Figure 12.1. The Social Relations Model effects.

The actor effect reflects a family member's tendency to act to all other family members in a particular manner. In the example, the actor effect describes the father's tendency to be committed to all family members. The partner effect reflects a tendency for a family member to be regarded by all family members in a particular manner. In the example, the partner effect measures the tendency for the adolescent child to elicit commitment from all other family members. The relationship effect describes the unique aspects of the relationship between two individuals after both actor and partner effects have been statistically removed. In the example, the relationship effect measures the father's commitment to the adolescent after controlling for the father's general tendency to be committed to other family members in general and the adolescent's general tendency to elicit commitment from other family members. Note that the relationship effect is directional in that the relationship effect for the father with the adolescent may differ from the relationship effect for the adolescent with the father. The family effect represents the unique 
aspects of the family as a group. In the example, it reflects the general level of commitment in the family, that is, the commitment of all family members to all family members. Additionally, the SRM considers error variance which reflects any remaining variance that is due to error.

These different effects in dyadic scores can be described by the following formula:

$$
\mathrm{X}_{i j k}=\mu_{k}+\alpha_{i k}+\beta_{j k}+\gamma_{i j k}+\varepsilon_{i j k}
$$

in which $\mathrm{X}_{i j k}$ is the reported dyadic score (for example the commitment in a family dyad of actor $i$ with partner $j$ in family $k$ ) and $\varepsilon_{i j k}$ represents the error term. The actor effect is $\alpha_{i k}, \beta_{j k}$ is the partner effect, and $\gamma_{i j k}$ is the relationship effect. Usually, $\mu$ represents the constant term, but when groups such as families are studied, $\mu_{k}$ represents the mean level of scores within the family as a whole, or the family effect.

Generally, there will be variability across families in the measured variables. For example, typically fathers will differ across families in the commitment to their adolescent children. The SRM is used to identify the sources of this variability. In three-person families, each of the possible six relationships consists of four sources of variance: actor variance, partner variance, relationship variance, and family variance. The actor variance for any given role measures the degree of variation in actor effects for that role. Using the commitment example, a very small estimate of actor variance for adolescents would indicate that adolescents across all families tend to be similarly committed to all other family members. Similarly, the partner variance measures the variability in partner effects for each role. For example, large estimates of partner variance for adolescents would indicate that some adolescents elicit much commitment from all other family members, whereas other adolescents do not elicit much commitment from all other family members. Relationship variance for each dyadic combination of roles (e.g., mothers' commitment to fathers, mothers' commitment to adolescents) can also be estimated. For example, large relationship variance for mothers' commitment to fathers would indicate that in some families, mothers are very committed to fathers, whereas in other families, mothers are not committed to fathers. Finally, variance in the family means can be estimated. This would reflect the extent to which commitment differs across families. For example, all members of a family are more committed to each other compared to all members of other families.

In addition to these four effects, the SRM enables estimation of various meaningful correlations between effects. Two of these important correlations are individual and dyadic reciprocity. Individual reciprocity refers to the correlation between a person's actor effect and that person's partner effect. 
For example, positive individual reciprocity for mothers examines whether mothers who are committed to all their family members elicit commitment from all their family members as well. Dyadic reciprocity refers to the correlation between two persons' relationship effects and measures the degree of similarity or dissimilarity between two individuals' relationship effects. For example, positive dyadic reciprocity for the mother-adolescent dyad examines whether mothers are committed to their adolescent when their adolescent is committed to them. Individual and dyadic reciprocity can also be negative, for example, if the father is committed to others, but others tend to be less committed to the father.

\section{OVERVIEW}

As we have shown the SRM provides us with the unique opportunity to theoretically and methodologically disentangle different levels of influence in family relationships. In the following we will present a study that allows us to illustrate different applications of the SRM to family relationships. Rather than applying the SRM to the investment model in general, we will focus on three specific applications of the SRM to highlight its usefulness for the empirical investigation of truly relational phenomena and independent data. Specifically, after having introduced the study, we will present findings on the univariate SRM analyses of the investment model to demonstrate how the SRM allows us to disentangle and quantify actor, partner, relationship, and family effects in the investment model in families. Then, we will present findings of the multivariate analyses of aspects of the investment model to demonstrate the utility of the SRM for the investigation of longitudinal relations. Finally, we will present one example of how the SRM can be used to examine individual outcomes by considering all levels of influence in a family over time. Specifically, we will present our findings on how relationship commitment and satisfaction may predict adolescent depression over time.

Our aims of the presentation of this selection of applications of the SRM to the investment model in families are threefold. First, we want to provide readers with a general overview of how the SRM can be used in the family context. Second, we aim to explain and describe the SRM in such a fashion that the model become more accessible to researchers investigating relational phenomena with interdependent data. Third, we aim to shed some light on the practicality and rich possibilities the SRM offers for empirical research on relational phenomena. 


\section{METHOD}

Participants. Data of this study come from the first and second wave of the family sample of the CONAMORE study (CONflict And Management Of Relationships, Meeus et al., 2004), in which 1313 early and middle adolescents participated longitudinally. At the first measurement, all early adolescents received a letter including an invitation to participate with both parents during annual home-visits as well. Of the families invited, 491 families initially agreed to participate. Due to our restriction of including only two-parent families, 90 one-parent families who agreed to participate were not able to take part in this additional research project. Finally, after some families had decided to withdraw from participation, 323 families participated in the study from wave two onwards. The current study uses data from this family sample, in which father, mother, and adolescent participated. The vast majority (99\%) of the adolescents in the family sample was of Dutch origin. Adolescents came from 12 schools in Utrecht and surroundings. Different educational levels were represented, with approximately $1 / 3$ of the adolescents being in schools preparing for blue collar work, $1 / 3$ of the adolescents in schools preparing for higher professional education, and $1 / 3$ of the adolescents in schools preparing for university (because classes are often combinations of different school levels, exact numbers cannot be provided).

Procedure. Before the start of the study, students and their parents received written information and, if the students agreed to participate, were required to provide written informed consent; less than $1 \%$ refused to participate. Written informed consent was also obtained at all the participating schools. In each of the two waves with a one-year interval, interviewers visited schools and asked participating adolescents to fill out a battery of questionnaires after school hours. During school visits the interviewer started with an explanation of the project and instruction about filling out the questionnaire. Anonymity and confidentiality were guaranteed explicitly. The interviewer asked the adolescents to fill out the questionnaires individually. The presence of the interviewer encouraged complete responding and prevented collaboration among the adolescents as they completed the questionnaire. In both waves, respondents received $€ 10$ after completing the questionnaires.

Measures. Participants completed a large battery of questionnaires including measures on relationship satisfaction, quality of alternatives, investment level and relationship commitment. Adolescents rated these measures for father and mother and parents rated their spouse and child.

Investment model scale. Investment model variables were assessed by a Dutch adaptation of the Investment Model Scale (Rusbult, Martz, \& Agnew, 1998), an instrument designed to measure commitment level, satisfac- 
tion level, investment size, and quality of alternatives that has good reliability and validity. Commitment level refers to the intent to maintain a relationship and to feel attached to it, and was assessed with four items. For example: "I wish the relationship with my ..... were to stay the way it is." Satisfaction assesses the extent to which participants are satisfied with their relationship or experience positive and negative affect in their relationship. This scale was assessed with four items. An item example is: "I am satisfied with the relationship with my ..." Investment size refers to the number, magnitude, and importance of resources that are put into a particular relationship that cannot be retrieved if the relationship ends, and was assessed with five items. An example item is: "I lose a lot if the relationship with my ..... gets worse." Quality of alternatives assesses the rewards and costs that are expected in the alternatives participants have for the relationship, or the perceived desirability of the best available alternative for the relationship, and was assessed with five items. For example: "I have many opportunities to do things with others than my ...." All items were answered on 5-point Likert scales. Across relationships, reliability coefficients (Cronbach's alphas) ranged from .82 to .94 for satisfaction (from .82 to .94 for parents and from .91 to .94 for adolescents), from .56 to .85 for investment (from .56 to .73 for parents and from .81 to .85 for adolescents), from .36 to .80 for alternatives (from .36 to .66 for parents and from .68 to .80 for adolescents), and from .65 to .89 for commitment (from .65 to .87 for parents and from .85 to .89 for adolescents). Lowest reliabilities appeared for Alternatives as perceived by parents.

Depression was measured with the Children's Depression Inventory (CDI; Kovacs, 1985, 1992), a symptom-based measure consisting of 27 items rated on a 3-point Likert scale ranging from not true to very true. Sample items are: "I worry all the time about all kind of things," "I feel tired all the time", and "I don't have any friends." The CDI has adequate to good internal consistency and test-retest reliability (Finch, Saylor, Edwards, \& McIntosh, 1987) and adequate factor validity (Craighead, Smucker, Craighead, \& Ilardi, 1998). Cronbach's alpha for this measure in the current sample was .92.

\section{RESULTS}

\section{Univariate SRM Analyses}

Description of analyses. Social Relations Models in families are commonly estimated using confirmatory factor analysis, although other methods are available (see for example, Kenny, 1994; Snijders \& Kenny, 1999). The actor, partner, relationship, and family effects technically constitute separate factors or latent variables within a confirmatory factor analysis (see Figure 12.2; 


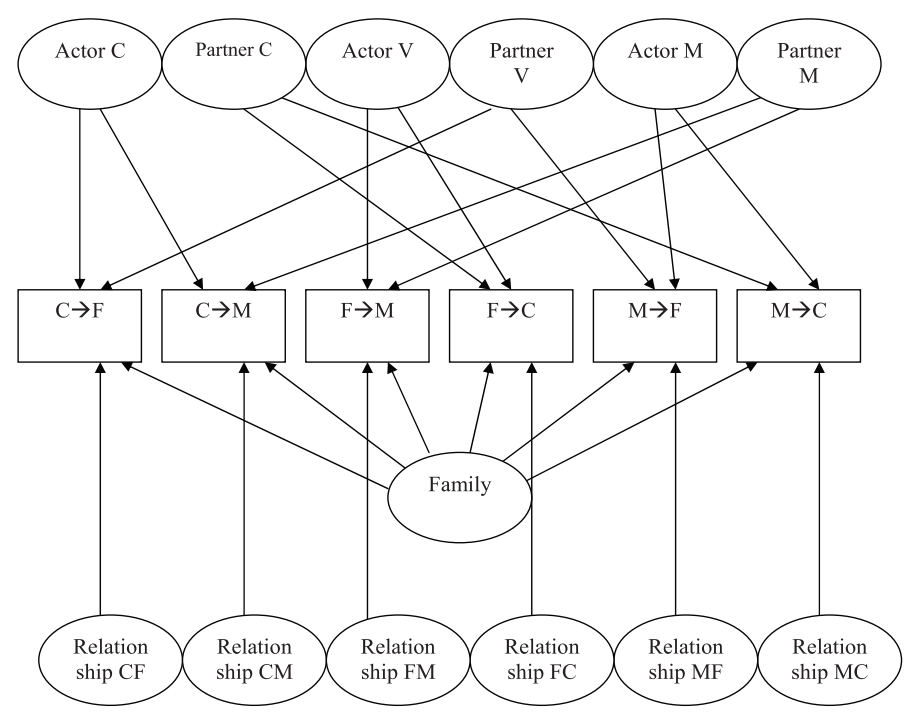

Figure 12.2. Parameters of the LISREL model.

Note. $\mathrm{F}=$ father, $\mathrm{M}=$ mother, $\mathrm{C}=$ child; $\mathrm{FM}=$ fathers' perception of mother, $\mathrm{FC}=$ fathers' perception of child, $\mathrm{MF}=$ mothers' perception of fathers, and so forth. Rectangles represent the observed measures; ellipses represent the latent SRM components. Doubleheaded arrows represent dyadic reciprocity correlations. All of the observed variables loaded on the latent SRM component "family variance," which is not included in the figure. Figure 12.2 displays the parameters for one indicator of perceived support only; the other indicator loads on the same latent factors in a similar manner.

Cook, 1994). A structural equation modeling program can be used to perform the confirmatory factor analysis (e.g., LISREL, Jöreskog \& Sörbom, 1996). A minimum sample size of 50 families is required to have enough power for an SRM analysis (Kashy \& Kenny, 1990). A sample size of 323 families, such as in the present study, is therefore more than adequate.

In a three-person family, six variables are obtained. In families composed of a mother $(\mathrm{M})$, a father $(\mathrm{F})$, and a child $(\mathrm{C})$, these variables are, for example, mother's commitment to father (MF), mother's commitment to the adolescent child (MC), father's commitment to mother (FM), and so on. Thus, in a round-robin design, the six observed variables include MF, MC, FM, FC, $\mathrm{CM}$, and $\mathrm{CF}$. Note that in these abbreviations the first letter corresponds to the actor (the person making the rating), and the second letter corresponds to the partner (the person being rated). The variables are asymmetric in that MF is not necessarily the same as FM. The SRM components are estimated from the covariance matrix of these observed variables.

To partition the observed variance in the investment model variables in the SRM variance components, one has to specify which variable loads on 
TABLE 12.1

Parameters of the LISREL Model

\begin{tabular}{|c|c|c|c|c|c|c|c|c|c|c|c|c|c|}
\hline \multirow{4}{*}{$\begin{array}{l}\text { Observed } \\
\text { Variables }\end{array}$} & \multicolumn{13}{|c|}{ SRM Components (Latent Factors) } \\
\hline & \multirow{2}{*}{\multicolumn{3}{|c|}{$\begin{array}{l}\text { Actor } \\
\text { Effects }\end{array}$}} & \multirow{2}{*}{\multicolumn{3}{|c|}{$\begin{array}{l}\text { Partner } \\
\text { Effects }\end{array}$}} & \multirow{2}{*}{\multicolumn{6}{|c|}{$\begin{array}{l}\text { Relationship } \\
\text { Effects }\end{array}$}} & \multirow{3}{*}{$\begin{array}{l}\text { Family } \\
\text { Effect }\end{array}$} \\
\hline & & & & & & & & & & & & & \\
\hline & $\mathrm{F}$ & M & $\mathrm{C}$ & $\mathrm{F}$ & M & $\mathrm{C}$ & FM & FC & MF & $\mathrm{MC}$ & $\mathrm{CF}$ & $\mathrm{CM}$ & \\
\hline FM & 1 & 0 & 0 & 0 & 1 & 0 & 1 & 0 & 0 & 0 & 0 & 0 & 1 \\
\hline FC & 1 & 0 & 0 & 0 & 0 & 1 & 0 & 1 & 0 & 0 & 0 & 0 & 1 \\
\hline MF & 0 & 1 & 0 & 1 & 0 & 0 & 0 & 0 & 1 & 0 & 0 & 0 & 1 \\
\hline $\mathrm{MC}$ & 0 & 1 & 0 & 0 & 0 & 1 & 0 & 0 & 0 & 1 & 0 & 0 & 1 \\
\hline $\mathrm{CF}$ & 0 & 0 & 1 & 1 & 0 & 0 & 0 & 0 & 0 & 0 & 1 & 0 & 1 \\
\hline $\mathrm{CM}$ & 0 & 0 & 1 & 0 & 1 & 0 & 0 & 0 & 0 & 0 & 0 & 1 & 1 \\
\hline
\end{tabular}

Note. $\mathrm{F}=$ father; $\mathrm{M}=$ mother; $\mathrm{C}=$ child. Direction is presented as follows: $\mathrm{FM}=$ father's commitment to mother, $\mathrm{FC}=$ father's commitment to the child, $\mathrm{MF}=$ mother's commitment to father, and so forth.

which factors, or latent variables, in the confirmatory factor analysis. In the basic three-person family design, each observed variable loads on four general factors which represent the four effects described above: an actor factor, a partner factor, a relationship factor, and a family factor. For example, the commitment of mother to father loads on the mothers' actor factor, the fathers' partner factor, the mother $\rightarrow$ father relationship factor, and the family factor.

Similarly, the commitment of mother to the adolescent loads on the mothers' actor factor, the adolescents' partner factor, the mother $\rightarrow$ adolescent relationship factor, and the family factor. All six of the observed variables load on the family mean factor. The factor loadings (i.e., paths from the latent variables to the observed variables) are usually fixed at 1.0, and the SRM factor variances are the parameters to be estimated (Kashy \& Kenny, 1990).

Table 12.1 shows how the observed variables load on the latent variables. Forcing the observed variables to load on the appropriate factors enables us to estimate the amount of variance in the observed variable accounted for by each of the factors. The variance of each factor (e.g., the mother actor factor) estimates the variance in the corresponding SRM component (e.g., the variance in the actor effects across mothers). In this design there are three factors for actor (F, M, and $\mathrm{C}$ actor), three factors for partner (F, M, and C partner), six relationship factors (one for each unidirectional relationship), 
and one family mean factor. Estimates of the actor and partner variance for each role, the six relationship variances, and the family variance can be found on the diagonal of the factor-by-factor covariance matrix.

Relationship variance describes variance in the unique level of commitment of one family member (e.g., mother) to another (e.g., adolescent). For the three-person family design, there are six relationship variances, one for each variable. However, to reliably estimate the six relationship components (that is, without random error), at least 12 variables are needed. In order to separate true relationship effects from error, replications of each of the observed variables need to be obtained. One option is to measure each variable at two or more times. Another option is to use two or more different measures and treat these as indicators of one theoretical construct. In the current study, the second option was used and two parcels were created for each of the investment model variables. The two or more replications are considered as indicators of a relationship factor as well as indicators of the relevant actor, partner, and family factors (Cook, 1993, 1994, 2000).

To be able to reliably estimate all SRM variance components as well as all possible correlations between these variance components, at least four members of each family have to participate in the study (Cook, Kenny, \& Goldstein, 1991; Kashy \& Kenny, 1990). To be able to estimate all SRM variance components in three-person families, one cannot estimate all possible correlations between variance components. Therefore, we did not estimate all possible correlations. For example, we did not estimate correlations between relationship effects of children with fathers and mother (so-called intergenerational assimilation) or correlations between relationship effects of fathers and mothers with children (so-called intergenerational consensus). Instead, only individual and dyadic reciprocity for significant variance components were estimated.

Thus, in four separate SRM analyses, for satisfaction, investments, alternatives, and commitment, we explored the extent to which variance in commitment, satisfaction, investment, and quality of alternatives in each of the six family relationships is due to actor, partner, relationship, and family effects. All these effects are estimated independently, controlling for all remaining effects. That is, a relationship effect is estimated after controlling for actor, partner, and family effects. We allowed for correlations among measurement errors for each indicator per rating family member (e.g., for each indicator of father's commitment, we allowed father's measurement errors for their commitment to mother and adolescent to correlate). The different variances were simultaneously estimated using structural equation modeling with maximum likelihood estimation procedures (LISREL 8.54, Jöreskog \& 
Sörbom, 1996). Missing data were estimated in LISREL using the FIML approach.

After estimating the SRM variance components, the correlations between different significant variance components can be specified, for example to estimate individual and dyadic reciprocity effects. Estimates of individual reciprocity for each role (the covariance between actor and partner effects such as the covariance between the mother actor factor with the mother partner factor) and the three measures of dyadic reciprocity (the covariance between relationship effects $\mathrm{MF}-\mathrm{FM}, \mathrm{MC}-\mathrm{CM}$, and $\mathrm{FC}-\mathrm{CF}$ ) can be found in the off-diagonal of the factor covariance matrix.

The statistical significance of each parameter estimate (i.e., actor, partner, relationship, and family variances) can be evaluated. For tests of variance, the key question is whether the variance is greater than zero, since the estimated variances must be positive. In testing for the significant presence of SRM variance components, the tests should be one-tailed, assuming that the estimated variances are positive.

In addition to the individual parameter tests, the overall fit of the model is generally evaluated by a chi-square goodness-of-fit test or other goodness-offit indices such as the Root Mean Square Error of Approximation (RMSEA) (M. Browne \& Cudeck, 1989; M. W. Browne \& Cudeck, 1993; Kenny, 2001, February 22). These indices assess the success of the proposed model to adequately reproduce the observed covariation among the variables. RMSEA values up to .05 represent a close fit and values up to .10 represent reasonable errors of approximation in the population (M. Browne \& Cudeck, 1989; M. W. Browne \& Cudeck, 1993; Hu \& Bentler, 1999; Kenny, 2001, February 22). Also, it is possible to use goodness-of-fit tests to compare two alternative models, one of which is a simpler version of the other. In this way, an initial model can be modified by making it more complex or simple, and these changes can be statistically evaluated.

Once the basic model has been estimated, simpler versions of the model can be estimated and compared with the basic model. In equality-of-parameter tests, one takes a given set of parameters (e.g., actor variances) and forces them to equal the same value. This allows one to test whether or not the parameters differ significantly by family role (e.g., whether mother's actor variance actually differs from father's actor variance). Similarly, sets of parameters (e.g., actor variances) can be fixed to zero to evaluate whether a given component (e.g., actor variance) or correlation between components (e.g., dyadic reciprocity) is supported by the data. By comparing the fit of these restricted versions of the model (the models in which some components are set to zero or set equal) to the fit of the unrestricted model, one can evaluate whether the unrestricted model is indeed the best fitting model. If 
TABLE 12.2

Fit Indices of SRM Analyses

\begin{tabular}{llll}
\hline & $\chi^{2}$ & $\mathrm{df}$ & RMSEA \\
\hline Univariate SRM Analyses & & & \\
Satisfaction & $91.93^{* *}$ & 43 & .06 \\
Investments & $71.18^{* *}$ & 46 & .04 \\
Quality of Alternatives & $91.15^{*}$ & 47 & .05 \\
Commitment & $101.29^{* *}$ & 47 & .06 \\
Commitment T2 & $102.62^{* *}$ & 45 & .06 \\
\hline $\begin{array}{l}\text { Multivariate longitudinal SRM } \\
\text { Analyses }\end{array}$ & & & \\
Commitment $\rightarrow$ Commitment T2 & $603.73^{* *}$ & 242 & .07 \\
Satisfaction $\rightarrow$ Commitment T2 & $1574.98^{* *}$ & 578 & .07 \\
Investments $\rightarrow$ Commitment T2 & $1376.82^{* *}$ & 580 & .06 \\
$\begin{array}{l}\text { Quality of Alternatives } \rightarrow \\
\text { Commitment T2 }\end{array}$ & $1223.47^{* *}$ & 582 & .06 \\
\hline
\end{tabular}

the chi-square is significantly higher in the restricted model, the restriction on the model significantly worsens the fit. One can then conclude that a variance component is supported by the data, or that there is a difference between variance components for family members with different roles.

Univariate SRM analyses of the investment model. Separate SRM analyses were performed for each investment model variable to partition the variance in satisfaction, investments, quality of alternatives, and commitment into actor variance, partner variance, relationship variance, and family variance. We allowed for correlations among measurement errors for each indicator per rating family member (e.g., we allowed correlations between measurement errors for the two indicators of father's commitment to mother). The goodnessof-fit indices are presented in Table 12.2. These indices showed that the fit of these models was fairly acceptable, indicating that the SRM components can be used to adequately represent the investment model in families.

Results of the univariate SRM analyses are displayed in Table 12.3 (the first four columns present the results for Time 1). For each of the six dyadic relationships, the percentage of the variance in the investment model variables explained by the SRM components was calculated. For example, the total explained variance in fathers' commitment to mothers consists of four variance components: (1) the actor variance among the fathers (see Table 12.3, $.09)$, (2) the partner variance of the mothers (.00), (3) the father $\rightarrow$ mother relationship variance (.19), and (4) the family variance (.02). The relative 
TABLE 12.3

SRM Variance Estimates for Satisfaction, Investments, Quality of Alternatives, and Commitment and Correlations Between SRM Components

\begin{tabular}{|c|c|c|c|c|c|}
\hline & Satisfaction & Investments & $\begin{array}{c}\text { Quality of } \\
\text { Alternatives }\end{array}$ & Commitment & $\begin{array}{c}\text { Commitment } \\
\mathrm{T} 2\end{array}$ \\
\hline \multicolumn{6}{|l|}{ Actor Variance } \\
\hline Child & $.24^{* *}$ & $.29 * *$ & $.24^{* *}$ & $.25^{* *}$ & $.27^{* *}$ \\
\hline Father & $.08^{* *}$ & $.09^{* *}$ & $.06^{* *}$ & $.09^{* *}$ & $.08^{* *}$ \\
\hline Mother & $.07^{* *}$ & $.07 * *$ & $.04 * *$ & $.08 * *$ & $.08^{* *}$ \\
\hline \multicolumn{6}{|l|}{ Partner Variance } \\
\hline Child & $.09 * *$ & .01 & .00 & .00 & .02 \\
\hline Father & $.08^{* *}$ & .02 & .02 & .01 & .02 \\
\hline Mother & .00 & .00 & .01 & .00 & $.07 * *$ \\
\hline \multicolumn{6}{|l|}{ Relationship Variance } \\
\hline Child-father & $.11^{* *}$ & $.13^{* *}$ & $.08^{* *}$ & $.17^{* *}$ & $.24^{* *}$ \\
\hline Child-mother & $.12 * *$ & .02 & .00 & $.09 * *$ & .00 \\
\hline Father-child & $.08 * *$ & $.05^{* *}$ & .02 & $.09^{* *}$ & $.07^{* *}$ \\
\hline Mother-child & $.10^{* *}$ & $.04^{* *}$ & $.04 *$ & $.12 * *$ & $.11^{* *}$ \\
\hline Father-mother & $.41^{* *}$ & $.17^{* *}$ & $.09^{* *}$ & $.19^{* *}$ & $.26^{* *}$ \\
\hline Mother-father & $.43^{* *}$ & $.13 * *$ & $.08^{* *}$ & $.21^{* *}$ & $.33^{* *}$ \\
\hline Family Variance & $.08^{* *}$ & $.03^{* *}$ & $.03^{* *}$ & $.02 * *$ & .01 \\
\hline
\end{tabular}

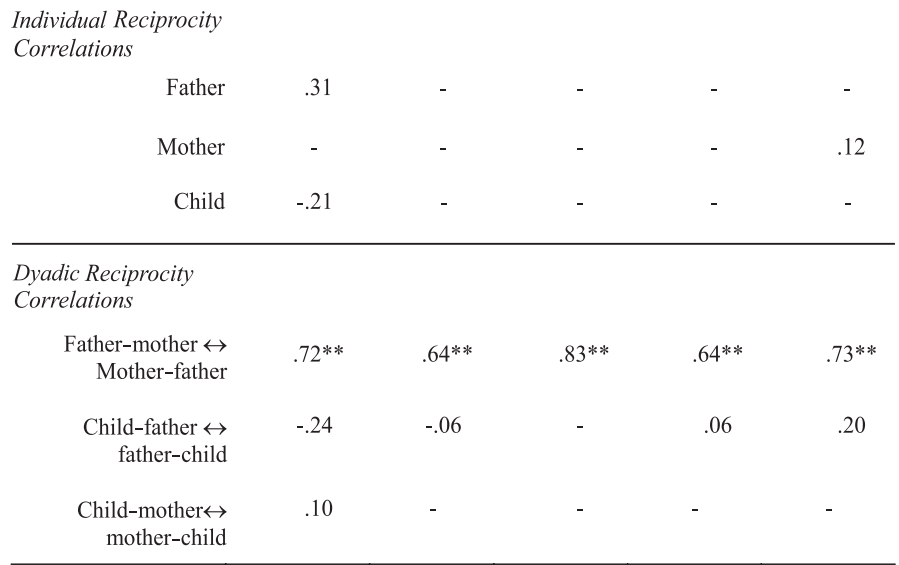

Note. Dashes indicate covariances that were not estimated because there was no significant variance in one or both of the variables.

${ }^{*} p<.05 ;{ }^{* *} p<.01$. 


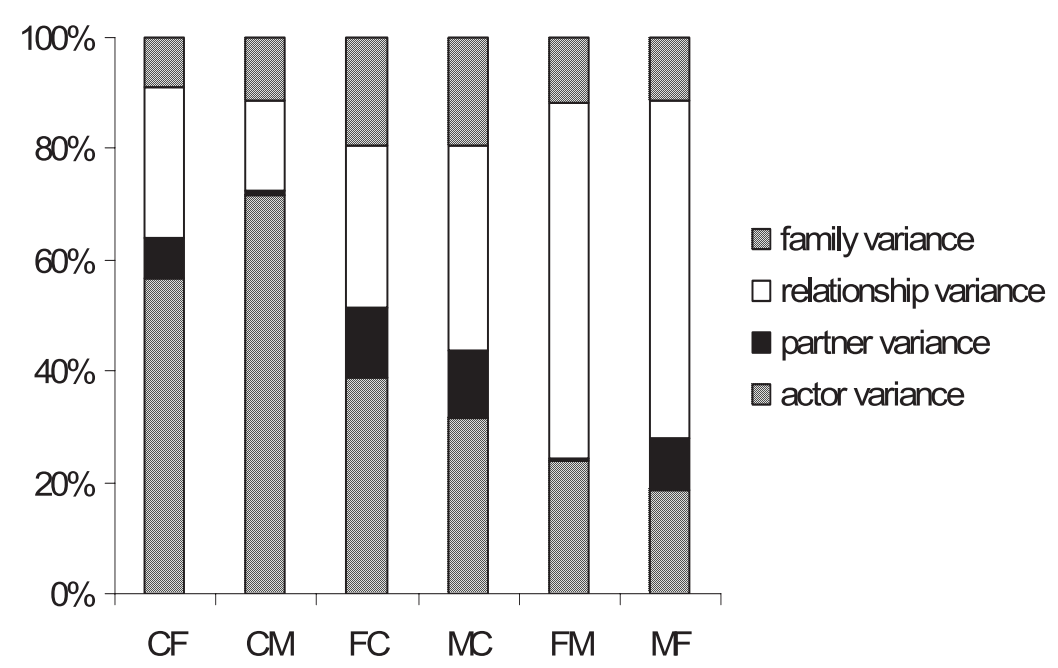

Figure 12.3. Percentage of variance explained by SRM components.

Note. $\quad \mathrm{FM}=$ fathers' perception of mother, $\mathrm{FC}=$ fathers' perception of child, $\mathrm{MF}=$ mothers' perception of fathers, and so forth.

actor variance in fathers' commitment to mothers is computed by dividing the fathers' actor variance by the total explained variance in fathers' commitment to mothers (i.e., .09/.30 = 30\%). The contributions of the different SRM components to the variance in the dyadic relationships were next averaged across the four variables of the investment model. In Figure 12.3, the relative amounts of variance accounted for by the four SRM components are presented. The mean relative actor variance, partner variance, relationship variance, and family for each of the six unilateral relationships are presented separately.

For each of the three family members, significant actor variance was found as indicated by the $t$-values of the coefficients in the psi-matrix. This means that differences in relationship satisfaction, investment, quality of alternatives, and commitment across families are at least in part due to differences in the actors' generalized tendency to be satisfied, to invest, to have alternatives, or to be committed. Some fathers, mothers, and adolescents report more satisfaction, investment, quality of alternatives, and commitment to all family members than other fathers, mothers, and adolescents. Actor variance was much higher for adolescents than for parents, explaining on average $64 \%$ of the total explained variance in adolescents' relationships (Figure 12.3). Actor effects contributed especially to variance in children's relationship with mothers. Actor effects contributed least to the variance in the horizontal 
marital relationship (on average $21 \%$ ). Actor effects might contribute more to the variance for children than for parents because in this study children rate two persons in a comparable role (i.e., parents) whereas parents rate two persons in different roles (i.e., spouse and child). However, other studies have found comparable differences in the contribution of actor variance to ratings of children versus parents in four-person families (Branje, van Aken, \& van Lieshout, 2002; Branje, van Aken, van Lieshout, \& Mathijssen, 2003).

Significant partner variance was found only for satisfaction of fathers and children. This indicates that characteristics of fathers and children in part account for the satisfaction that family members experience in their relationships with fathers and children. Some fathers and adolescents elicit more satisfaction from all family members than other fathers and adolescents. On average, partner effects only explained $7 \%$ of the total explained variance. For mothers, no significant partner variance was found in Time 1 investment model variables. Also, for the other investment model variables, no significant partner variance was found. These nonsignificant partner variances indicate that there is little consensus among family members regarding their satisfaction with, investments to, alternatives for, and commitment to specific individual family members. Put differently, in all families certain roles elicit different responses or perceptions from all other family members such that for mothers for example no partner variances are observed.

Differences in investment model variables can be attributed to differences in the particular combination of actor and partner in all dyadic family relationships, as indicated by the significant relationship variances (Table 12.3). For example, the significant relationship variance for fathers' commitment to children indicates a unique component in the commitment that fathers have to their child when compared to the commitment that fathers have to their spouse. The contribution of relationship effects to the total variance varied a lot, ranging from $0 \%$ to $72 \%$. Relationship variance was particularly large in the marital relationship, explaining on average $62 \%$ of the variance. In the relationships of parents to children and of children to fathers, relationship effects explained on average $31 \%$ of the variance and in the relationship of children to mothers relationship effects explained the least amount of variance, on average $16 \%$. In other words, in the horizontal marital relationship much of the behavior and perception is determined by the specific relationship, above and beyond any other influence. Thus, relationships between marital partners are relationship specific and do not generalize to other types of relationships.

Differences in investment model variables can also be attributed to differences in the mean family level of these variables across families, as indicated by significant family variance. The family effect explained on average $14 \%$ of 
the total explained variance (see Table 12.3). It can be concluded that families clearly differ in the level of commitment and investment variables within the family as a whole. Family variance explained most of the total explained variance in parents' relationships with their children.

We also estimated individual and dyadic reciprocity correlations for significant SRM variances. These correlations are estimated as the relations among the latent variables in the CFA. The correlations between significant actor and partner variances (i.e., individual reciprocity) and significant relationship variances (i.e., dyadic reciprocity) are presented in Table 12.3. Results show that actor and partner variances were not significantly related. Relationship variances were significantly and strongly related within the marital relationship only. These findings indicate that dyadic reciprocity is important in the marital relationship but not in other family relationships. So, if mother is especially satisfied with her relationship with father, father is especially satisfied with his relationship with mother too.

To summarize, the SRM can be meaningfully applied to disentangle and quantify the influence of different levels of relational phenomena in the family. The results provide unique insights in differences between different relationship types. Specifically, in our findings, horizontal relationships between marital partners show distinct patterns of influences as compared to vertical relationships between parents and children. Marital relationships seem to be more strongly determined by the specific interaction between the relationship partners, whereas in parent-child relationships the individual characteristics of the child play an important role.

\section{Multivariate SRM Analyses: Concurrent and Longitudinal Associations of Satisfaction, Investments, and Alternatives With Commitment}

To demonstrate the utility of SRM for concurrent and longitudinal research, we estimated the links between SRM components of the investment model variables with commitment both concurrently and over time in multivariate SRM analyses. Because a model including commitment at both time points as well as satisfaction, investments, and alternatives in a single comprehensive model would be too complicated, we opted for a stepwise and pairwise procedure. First, we examined the stability of the SRM variances of commitment over time. Next, we performed three separate multivariate analyses that included satisfaction, investments, and alternatives with commitment at both time points in a pairwise fashion.

First, we estimated a stability model of commitment, in which significant Time 2 SRM variance components of commitment were predicted from sig- 
TABLE 12.4

Correlations Between SRM Components Across Investment Model Variables

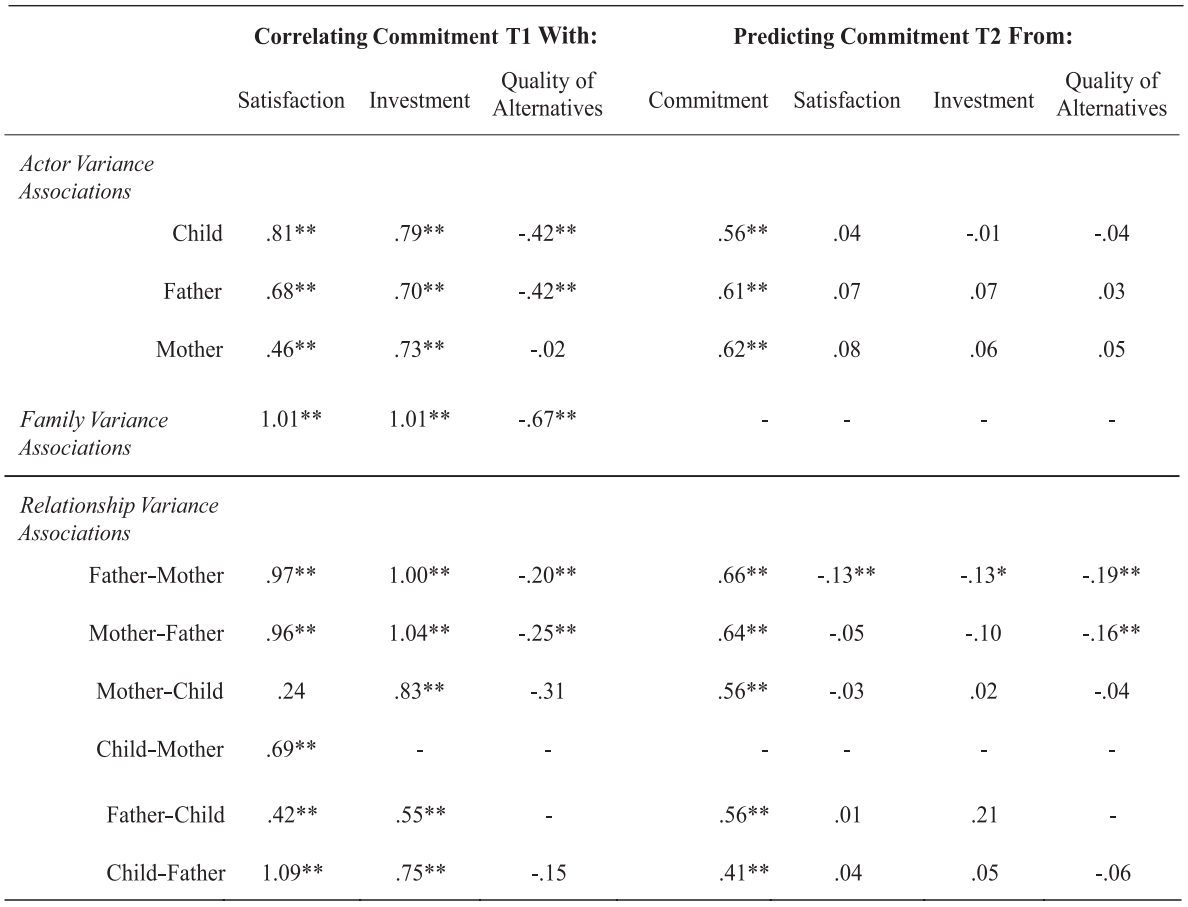

Note. Dashes indicate covariances that were not estimated because there was no significant variance in one or both of the variables.

$p<.05 ; * * p<.01$.

nificant Time 1 SRM variance components of commitment. That is, we estimated the directional effect of the commitment family variance Time 1 on the commitment family variance Time 2 , the directional effect of the commitment father-actor variance Time 1 on the commitment father-actor variance Time 2, etc. Values for SRM variances were fixed at the estimates from the univariate models of commitment Time 1 and Time 2. Errors of the two indicators of each relationship within time points were again allowed to correlate, as well as errors of similar indicators across time (e.g., measurement errors of the first indicator of fathers' commitment to mother at Time 1 and Time 2 were allowed to correlate). Fit indices of this model are displayed in Table 12.2 and results are presented in Table 12.4, fifth column with the heading Commitment. Results indicate that all variance components are moderately stable over a one year period, ranging from .41 to .66.

Second, we estimated relations of satisfaction, investments, and alternatives with commitment both concurrently and over time. To be able to esti- 
mate this model, values for SRM variances were fixed at the estimates from the univariate models, and the stability effects of the SRM commitment variances from Time 1 to Time 2 were fixed at the values found in the stability model. Again, errors of the two indicators of each relationship within time points as well as errors of similar indicators across time were allowed to correlate. Thus, three separate SRM analyses were performed with Time 1 and Time 2 commitment and either Time 1 satisfaction, investments, or alternatives, to relate the significant actor, partner, relationship, and family effects of commitment to the significant SRM effects of the other investment model variables. More specifically, the family variance of one variable was related to the family variance of the other, the father-actor variance of one variable with the father-actor variance of the other, etc. The models showed an acceptable fit with our data set given the complexity of the models and the number of variables involved (see Table 12.2).

Concurrent relations between investment model variables in family relationships. We will first discuss concurrent links between investment model variables in family relationships (see Table 12.4, 2nd to 4th column). To examine whether more committed family members generally invest more, are more satisfied and have less alternatives as has been found in romantic relationships (cf., Rusbult, 1983), the correlations between a family member's actor effect for commitment and that family member's actor effect for satisfaction, investment and alternatives were computed. Errors of the two indicators of each relationship within time points were again allowed to correlate, as well as errors of similar indicators across time. The significant and strong correlations of actor effects indicate that individuals who are more committed to all their family members are more satisfied with, invest more, and - to a lower extent-have less alternatives to all family members. The correlations of partner variances were not computed because most of these variances were nonsignificant.

The family effect for commitment significantly and very strongly correlated with the family effect for satisfaction, investment, and alternatives, suggesting that in families where individuals are generally more committed the individuals are also generally more satisfied, invest more and have fewer alternatives. These relations generalize to the family as a group. As Jöreskog (1999) describes, these coefficients are structural coefficients, and can be larger than one in magnitude in the completely standardized solution.

The correlations between a family member's relationship effect for commitment and that family member's relationship effect for satisfaction, investment, and alternatives revealed that relationship effects were most strongly related in the horizontal marital relationship, followed by the child-father relationship. This shows that in particular marital partners who are more 
committed to their marital partner are also more satisfied, invest more, and have fewer alternatives for their partner. In the vertical mother-child, father-child, and child-mother relationship, relationship variances were generally less strongly related, although it should be noted that not all these relations could be estimated due to nonsignificant variances.

Overall, these findings indicate that the investment model can be extended to family relationships. It holds for individual members within the family but also for families as a group. Moreover, in line with our speculations, it seems to apply more in marital relationships than in parent-child relationships.

Longitudinal relations between investment model variables and commitment. Because the relationships between parents and children may become more horizontal over time, it is interesting to explore whether the concurrent results generalize over time. To explore these questions, in the same models, we also estimated the links of satisfaction, investment, and alternatives with commitment at Time 2 (Table 12.4, 6th to 8th column). Most of these effects over time were nonsignificant, except for the relationship-specific effects of quality of alternatives to commitment in the marital relationship and the relationship-specific effects of satisfaction and investments of fathers to their spouse to commitment to their spouse. Marital partners who have more alternatives are less committed to their marital partner over time. Also, but in contradiction to our hypotheses, men who are more satisfied with and invest more in the relationship with their spouse are less committed over time. The fact that most longitudinal effects occur in the marital relationship indicates that the investment model is most suited to predict commitment in marital relationships. Perhaps when children become young adults, the investment model will be more suited to predict commitment in the parent-child relationship.

Overall, SRM analyses suggest that the investment model can predict marital commitment over time. It is well suited for horizontal relationships between equal partners, but seems less suited for vertical relationships between unequal partners. Additionally, the analyses suggest that there is little variation across parent-child relationships neither concurrently nor over time. In the SRM, the absence of an effect may be interpreted in two ways. On the one hand, it is possible that the investment model is less important in parent-child relationships than it is in other relationships. Parent-child relationships are involuntary, that is neither parents nor children can choose to leave the relationship. Rather, they must continue to live with each other in good times and in bad times. On the other hand, the absence of SRM effects may also indicate that parent-child relationships are rated in a comparable fashion across all families who participated in our study. Because the social relations model does not allow us to distinguish between these two explana- 
tions, research must be designed to systematically compare the investment model in different family relationships with the investment model in other types of relationships that vary in voluntariness (e.g., adolescent friendships, romantic relationships, sibling relationships).

\section{Concurrent and Longitudinal Associations of Satisfaction and Commitment With Adolescents' Depression}

To illuminate the usefulness of SRM for family research, the last application that we want to describe here concerns the prediction of individual outcomes by considering different familial influences over time. For this illustration, we will focus specifically on two variables in the investment model, namely commitment and relationship satisfaction. Depression in adolescence has consistently been found to be related to the quality of children's relationship with their parents (Branje, Hale III, \& Meeus, 2008). The question that has remained unanswered, however, is whether adolescent depression is predicted by the quality of specific relationships the child has with his or her parents or by the quality of the relationships of the family as a group. This question can be tackled by using the SRM.

To predict adolescents' depression at Time 2 from the Time 1 SRM variance components of commitment and satisfaction, we estimated separate models for commitment and satisfaction. Values for SRM variances were again fixed at the estimates from the univariate models, and errors of the two indicators of each relationship within time points were allowed to correlate. We first estimated a baseline model with the SRM variances for either commitment or satisfaction and the stability of depression from Time 1 to Time $2(\beta=.46)$. Next, correlations of depression Time 1 with child actor variance, child partner variance, child-father and child-mother relationship variance, and family variance were added stepwise. Subsequently, effects of child actor variance, child partner variance, child-father and child-mother relationship variance, and family variance on depression Time 2 were added stepwise. Chi-square difference tests were performed to examine whether inclusion of a correlation or an effect improved model fit, and if not, the effect was removed from the model. Table 12.5 presents the fit statistics and model comparisons of these models.

Using the SRM to predict adolescent depression with commitment. For commitment, child actor variance was significantly related to depression Time 1 , as well as child-mother relationship variance (see Table 12.5, models 2 and 4 for commitment). When child actor variance and child-mother relationship variance were entered together in the model, model fit did not improve compared to a model with only one of these variances (see Table 12.5, model 6), 
and the correlation of child-mother relationship variance became nonsignificant. When adding effects on depression Time 2 while controlling for the correlation of the specific variable with depression Time 1, model comparisons revealed that child actor variance and child-mother relationship variance significantly predicted depression at Time 2 (see Table 12.5, models 7 and 10). However, when child actor variance and child-mother relationship variance were entered together in the model, model fit did not improve compared to a model with only one of these variances (see Table 12.5, model 11), and the effect of child actor variance became nonsignificant. Thus, the final model was model 10, including a significant negative correlation of child actor variance with depression Time $1(r=-.31)$ and a significant positive effect of child-mother relationship variance on depression Time $2(\beta=.28)$ while controlling for the correlation of child-mother relationship variance with depression Time 1. These results indicate that the child's general tendency to be committed to parents is negatively related to depression, and suggest that children who are more committed to mother have lower levels of depression. However, children who are more specifically committed to mother have higher levels of depression over time.

Using the SRM to predict adolescent depression with satisfaction. For satisfaction, child actor variance was significantly related to depression Time 1, as well as child-mother relationship variance, child-father relationship variance, and family variance (see Table 12.5, models $2,4,5$, and 6 for satisfaction). When child actor variance and child-mother relationship variance or child-father relationship variance were entered together in the model, model fit did not improve compared to a model with only one of these variances (see Table 12.5, models 7 and 8), and the correlations of child-mother relationship variance and child-father relationship variance became nonsignificant. When child actor variance and family variance were entered together in the model, model fit improved compared to a model with only one of these variances (see Table 12.5, model 9), and both correlations remained significant. When adding effects on depression Time 2 while controlling for the correlation of the specific variable with depression Time 1, model comparisons revealed that child-father relationship variance and child-mother relationship variance significantly predicted depression at Time 2 (see Table 12.5, models 13 and 14). However, when child-father relationship variance and child-mother relationship variance were entered together in the model, model fit did not improve compared to a model with only one of these variances (see Table 12.5, model 15 ), and both effects became nonsignificant. Therefore, we will discuss the results of models 13 and 14, including a significant negative correlation of child actor variance and family variance with depression Time $1(r=-.27$ and $r=-.32$, respectively), a significant positive effect of child-mother rela- 
TABLE 12.5

Fit Indices and Model Comparisons of SRM Analyses Predicting Depression

\begin{tabular}{lllll}
\hline & $\chi^{2}$ & df & $\Delta \chi^{2} / \Delta d f$ & RMSEA \\
\hline Commitment & & & & \\
1. Baseline model & $284.57^{* *}$ & 110 & & .07 \\
2. Model 1 + child actor effect T1 & $265.61^{* *}$ & 109 & $18.96 / 1^{* *}$ & .07 \\
3. Model 1 + child-father relationship effect T1 & $282.53^{* *}$ & 109 & $2.04 / 1$ & .07 \\
4. Model 1 + child-mother relationship effect T1 & $277.91^{* *}$ & 109 & $6.66 / 1^{* *}$ & .07 \\
5. Model 1 + family effect T1 & $283.86^{* *}$ & 109 & $.71 / 1$ & .07 \\
6. Model 2 + child-mother relationship effect T1 & $265.48^{* *}$ & 108 & $.13 / 1$ & .07 \\
& $261.14^{* *}$ & 108 & $4.47 / 1 *$ & .07 \\
7. Model 2 + child actor effect T2 & $262.87^{* *}$ & 107 & $2.74 / 2$ & .07 \\
8. Model 2 + family effect T1+2 & $262.12^{* *}$ & 107 & $3.49 / 2$ & .06 \\
9. Model 2 + child-father relationship effect T1+2 & $252.80^{* *}$ & 107 & $8.57 / 2^{*}$ & .06 \\
$\begin{array}{l}\text { 10. Model 2 + child-mother relationship } \\
\text { effect T1+2 }\end{array}$ & & & & .07 \\
11. Model 10 + child actor effect T2 & $252.68^{* *}$ & 106 & $.12 / 1$ & .07 \\
\hline
\end{tabular}

\section{Satisfaction}

1. Baseline model

$275.25^{* *} \quad 110$

.07

2. Model $1+$ child actor effect $\mathrm{T} 1$

$250.13 * * \quad 109 \quad 25.12 / 1 * * \quad .06$

3. Model $1+$ child partner effect $\mathrm{T} 1$

$272.80 * * \quad 109 \quad 2.45 / 1 \quad .07$

4. Model $1+$ child-father relationship effect $\mathrm{T} 1$

$271.14 * * \quad 109 \quad 4.11 / 1^{*} \quad .07$

5. Model $1+$ child-mother relationship effect T1

$\begin{array}{llll}268.44 * * & 109 & 6.81 / 1 * * & .07\end{array}$

6. Model $1+$ family effect $\mathrm{T} 1$

$252.36^{* *} \quad 109 \quad 22.89 / 1^{* *} \quad .06$

7. Model $2+$ child-father relationship effect T1

$250.08^{* *} \quad 108 \quad .05 / 1 \quad .06$

8. Model $2+$ child-mother relationship effect $\mathrm{T} 1$

$250.08^{* *} \quad 108 \quad .05 / 1 \quad .06$

9. Model $2+$ family effect $\mathrm{T} 1$

$239.45^{* *} \quad 108 \quad 10.68 / 1^{* *} \quad .06$

10. Model $9+$ child actor effect T2

$239.22 * * \quad 107 \quad .23 / 1 \quad .06$

11. Model $9+$ family effect $\mathrm{T} 2$

$237.87 * * \quad 107 \quad 1.58 / 1 \quad .06$

12. Model $9+$ partner effect $\mathrm{T} 1+2$

$239.21 * * \quad 106 \quad .24 / 1 \quad .06$

13. Model $9+$ child-father relationship

$233.32 * * \quad 106 \quad 6.13 / 1^{*} \quad .06$ effect $\mathrm{T} 1+2$

14. Model $9+$ child-mother relationship effect $\mathrm{T} 1+2$

$230.88^{* *} \quad 106 \quad 8.57 / 1^{* *} \quad .06$

15. Model $13+$ child-father and child-mother relationship effect $\mathrm{T} 1+2$

Note. ${ }^{*} p<.05 ;{ }^{* *} p<.01$. 
tionship variance on depression Time $2(\beta=.22)$, and a significant negative effect of child-father relationship variance on depression Time $2(\beta=-.21)$ while controlling for the correlation of child-mother relationship variance with depression Time 1. These results indicate that the child's general tendency to perceive satisfaction from parents and the general level of satisfaction at the family level are negatively related to depression, and children who perceive more specific satisfaction with father have lower levels of depression over time, while children who perceive more specific satisfaction with mother have higher levels of depression over time.

More generally, these findings yield new insights in how the quality of family relationships can contribute to child depression. For both commitment and satisfaction it seems that good relationships in the entire family and good relationships with both parents serve as a protective factor. However, especially good relationships with one single parent may render an adolescent child more vulnerable to depression over time. The SRM thereby allows us to paint a more complete picture of how familial relationships may contribute to the development of depression in adolescents.

\section{CONCLUSION}

The selection of analyses presented in the current chapter show that the Social Relations Model can be used to estimate interdependent processes in family relationships. The SRM allows one to estimate four sources of variance at the level of the individual, the dyad, and the group (Kenny, 1994; Kenny \& La Voie, 1984). The actor effect reflects the tendency of the actor to judge all family members similarly. The partner effect reflects the extent to which all family members perceive a specific family member similarly. The relationship effect reflects whether a family member perceives specific relationship partners uniquely. Finally, the family effect reflects the extent to which all family members perceive all other members similarly. It thereby offers researchers interested in family relationships the possibility to disentangle the influence of different levels of influence and shed new light on relational phenomena that are inherently interdependent.

We began by investigating whether differences in the investment model can be attributed to differences in individual actors, individual partners, specific relationships, and family characteristics. The results of the Social Relations Analyses showed that family members' perceptions of investment model variables are more determined by the actor (or perceiver) than by the partner. The relatively strong influence of actor characteristics showed perceptions of others to be highly idiosyncratic, and may reflect a kind of working model based on earlier experiences that affects the expectations of all family mem- 
bers and relationships (Sarason, Pierce, \& Sarason, 1990). This underlines the importance of examining the subjective meanings that experiences and circumstances in the family have for individual family members. Because similar experiences may have very different meanings for different individuals, the same experiences may lead to different outcomes for different individuals. Family member's expectations about the partners' behavior might affect interactions and relationships between family members (Collins, 1991; 1997). These findings underline the importance of including multiple reporters within the family in a round-robin design. The SRM offers researchers the possibility to deal with the associated interdependence. The findings we obtained by using the SRM indicate that relying on single reports of others about a target individual may paint an incomplete picture of the relational influences at work in families. The results regarding family effects and relationship effects provide further support for this conclusion.

The family as a whole also contributed to differences in the investment model variables, which might indicate the importance of a general family climate. In some families, members seem to be more committed to and satisfied with each other, invest more and have fewer alternatives for their family relationships than in other families. In other words, some families are closer than others.

Although the characteristics of the perceiving individual and the family as a whole appeared to be important determinants of judgments about the investment model, characteristics of the specific dyadic family relationships also contributed to differences in judgments. Family members make unique responses to specific dyadic partners as shown by relationship effects. Horizontal marital relationships were characterized by higher relationship effects than vertical parent $\rightarrow$ child and child $\rightarrow$ parent relationships, indicating that the specific dyadic relationships were more important for horizontal relationships than for vertical relationships. In contrast to vertical relationship partners, horizontal relationship partners mutually reciprocate their unique perceptions. This shows the horizontal relationships to be largely dependent on the specific match between actor and partner.

These findings are compatible with our suggestions that horizontal relationship partners are more equal with regard to power, expertise, authority, and the exchange of affect than vertical relationship partners (Bugental \& Goodnow, 1998; Hartup, 1989). Moreover, they have important theoretical implications for the investment model in family relationships. In horizontal relationships, both partners have to continuously invest in their marital relationship and mutually coordinate and adjust their behavior, and the extent to which they do so may have the character of an exchange relationship more than in vertical relationships (Clark \& Jordan, 2002). If individuals in a hor- 
izontal relationship do not perceive the investment in the relationship to be reciprocated, then they may subsequently invest less and be less committed as a result. Because the horizontal relationship between marital partners is voluntary, the consequences of such a negative sequence of behavior may be dramatic. In the vertical parent-child relationship, however, parents may be committed to their children regardless of the investment of the children. The same might be the case for children toward parents, as children are typically loyal to their parents regardless of parental behaviors.

It should be noted, however, that the interpretation of SRM variance components in a three-person family differs from the interpretation in a fourperson family. In a four-person family with two parents and two children, judgments are balanced over generations, with each family member judging one family member of his or her own generation (i.e., the spouse or the sibling) and two members of the other generation (i.e., the two parents or the two children). In three-person families, adolescents judge two similar relationships (two parents) and father and mother judge two different relationships (spouse and child). The child actor effect may therefore reflect a "relationship type" effect and represent the child's general perception of parents. Thus, results of SRM analyses cannot be directly compared across studies examining families of different sizes or different composition, and researchers should always keep in mind the specifics of the families in their study to be able to interpret the results.

In four-person families, children's general perception of parents can be assessed as well, by correlating the relationship effects of child to father and child to mother. These correlations are referred to as intergenerational assimilation and measure the degree to which a person from one generation sees the persons of the other generation as similar (Branje, van Aken, \& van Lieshout, 2002; Finkenauer, Engels, Branje, \& Meeus, 2004; Kashy \& Kenny, 1990). For example, the degree to which the adolescent is equally committed to mother and father, or the degree to which mother is equally committed to both children. Another correlation assessing intergenerational interdependency that may be relevant in families in which the generation of the children may be distinguished from the generation of the parents, is intergenerational consensus, which measures the degree to which individuals from one generation view an individual from another generation as similar. For example, mother and father agree about how committed they are to the adolescent.

To demonstrate SRM's utility for the examination of the investment model in families both concurrently and longitudinally, we examined the relations of the variables of the investment model to commitment concurrently and over time. Based on these analyses, one can draw conclusions about whether associations between variables are stronger at the individual level, the dyadic level, 
or the family level. In the present study, concurrent associations between satisfaction, investment, and alternatives with commitment were strongest at the level of the family, indicating that families that are more committed also invest more, are more satisfied, and have fewer alternatives than families that are less committed. Concurrent relations were also strong at the level of the individual actor, and at the dyadic level for the marital relationship in particular. Relationship effects appeared to be the strongest predictors of commitment over time, but only in horizontal marital relationships. Please note that these covariances of relationship effects are evaluated after controlling for individual- and family-level covariances. These findings are in line with the idea that the investment model works best for exclusive dyadic relationships, although the direction of effects was sometimes opposite to our expectations (Lin \& Rusbult, 1995).

To demonstrate a third application of the SRM to family relationships, we predicted child depression over time from the SRM variance components of commitment and satisfaction. These analyses enable us to examine whether fathers and mothers have similar effects on child depression or whether it is important to distinguish between father and mother effects. As judgments of the child's relationship with father and mother are often highly related, it is difficult to decide how to handle these scores when using traditional analytic strategies. For example, entering scores on the relationship with father and mother in the same regression might lead to multicollinearity, performing separate analyses entails the risk that one is assessing the same relation two times, and combining or averaging father and mother scores might obscure differences in effects of father and mother. The SRM enables us to assess the effect of the child's general relationship with parents as well as the effect of the child's specific relationship to father and mother, thereby offering unique and exciting insights into the relation between family functioning and adolescent depression. Specifically, results indicated that concurrent relations with depression are due to the child's general relationship with both parents while effects over time are due to the child's specific relationship with mother or father. These results further underline the importance of considering different types of influence of relationships to enhance our understanding of the link between relationships and individual outcomes in general, and relationship quality and the development of adolescent depression in particular.

The current chapter only shows a few of the possibilities of the SRM in family relationships. The SRM could be extended in several ways. For example, instead of only correlating the same variances of different variables to each other (e.g., the child's actor variance of variable $\mathrm{X}$ to the child's actor variance of variable $\mathrm{Y}$ ), one could estimate correlations between different variances. An example is the work of Branje, van Lieshout, and van Aken (2002), 
who examined dyadic reciprocity across variables and found that individuals who are perceived as more agreeable by specific relationship partners perceive these relationship partners as more supportive. The SRM variances could also be related to self-judgments to examine assumed similarity (do family members perceive others as similar to themselves?) and self-other agreement (do family members perceive themselves similar as other members do?) (Kenny, 1994). For example, on most personality factors, the judgments of adolescents revealed a higher degree of self-other agreement and a lower degree of assumed similarity than those of parents (Branje et al., 2003). Further, Cook and colleagues (Cook \& Kenny, 2004) have focused on the SRM effects in individual families, which offer important possibilities for clinical practice.

To conclude, the SRM does not capture all possible complexity of family relationships but the model is certainly much more powerful for the study of complex family relationships than models that are typically used. In particular, instead of using just the judgment of single family members or aggregating judgments of several family members, the SRM enables one to assess the independent effects of the actor, the partner, their relationship, and the family on the interdependent judgments of all members in the family. 


\section{REFERENCES}

Bentler, P. M., \& Bonett, D. G. (1980). Significance tests and goodness-of-fit in the analysis of covariance structures. Psychological Bulletin, 88, 588-606.

Branje, S. J. T., Hale, W., III, \& Meeus, W. H. J. (2008). Reciprocal development of parent-adolescent support and adolescent problem behaviors. In M. Kerr, H. Stattin, \& R. Engels (Eds.), What can parents do? New insights into the role of parents in adolescent problem behaviour. New York: John Wiley \& Sons.

Branje, S. J. T., van Aken, M. A. G., \& van Lieshout, C. F. M. (2002). Relational support in families with adolescents. Journal of Family Psychology, 16, 351362.

Branje, S. J. T., van Aken, M. A. G., van Lieshout, C. F. M., \& Mathijssen, J. J. J. P. (2003). Personality judgments in adolescents' families: The perceiver, the target, their relationship, and the family. Journal of Personality, 71, 49-81.

Branje, S. J. T., van Lieshout, C. F. M., \& van Aken, M. A. G. (2002). Relations between agreeableness and perceived support in family relationships: Why nice people are not always supportive. International Journal of Behavioral Development, 29, 120-128.

Browne, M., \& Cudeck, R. (1989). Single sample cross-validation indices for covariance structures. Multivariate Behavioral Research, 24, 445-455.

Browne, M. W., \& Cudeck, R. (1993). Alternative ways of assessing model fit. In K. A. Bollen \& J. S. Long (Eds.), Testing structural equation models (pp. 132-162). Beverley Hills, CA: Sage.

Bugental, D. B., \& Goodnow, J. J. (1998). Socialization processes. In W. Damon (Ed.), Handbook of child psychology (5th ed.; Vol. 3, pp. 389-465). New York: John Wiley \& Sons.

Clark, M. S., \& Jordan, S. D. (2002). Adherence to communal norms: What it means, when it occurs, and some thoughts on how it develops. New Directions for Child and Adolescent Development, 95, 3-25.

Collins, W. A. (1991). Shared views and parent-adolescent relationships. NewDirections for Child Development, 51, 103-110.

Collins, W. A. (1997). Relationships and development during adolescence: Interpersonal adaptation to individual change. Personal Relationships, 4, 1-14.

Collins, W. A., Laursen, B., Mortensen, N., Luebker, C., \& Ferreira, M. (1997). Conflict processes and transitions in parent and peer relationships: Implications for autonomy and regulation. Journal of Adolescent Research, 12, 178-198.

Cook, W. L. (1993). Interdependence and the interpersonal sense of control: An analysis of family relationships. Journal of Personality and Social Psychology, $64,587-601$.

Cook, W. L. (1994). A structural equation model of dyadic relationships within the family system. Journal of Consulting and Clinical Psychology, 62, 500-509. 
Cook, W. L. (2000). Understanding attachment security in family context. Journal of Personality and Social Psychology, 78, 285-294.

Cook, W. L., \& Kenny, D. A. (2004). Application of the Social Relations Model to family assessment. Journal of Family Psychology, 18, 361-371.

Cook, W. L., Kenny, D. A., \& Goldstein, M. J. (1991). Parental affective style risk and the family system: A Social Relations Model analysis. Journal of Abnormal Psychology, 100, 492-501.

Craighead, W. E., Smucker, M. R., Craighead, L. W., \& Ilardi, S. S. (1998). Factor analysis of the Children's Depression Inventory in a community sample. Psychological Assessment, 10, 156-165.

Finch, J. J., Jr., Saylor, C. F., Edwards, G. L., \& McIntosh, J. A. (1987). Children's depression inventory: Reliability over repeated administrations. Journal of Clinical Child Psychology, 16, 339-341.

Finkenauer, C., Engels, R. C. M. E., Branje, S. J. T., \& Meeus, W. H. J. (2004). Disclosure and relationship satisfaction in families. Journal of Marriage and Family, 66, 195-209.

Hartup, W. W. (1989). Social relationships and their developmental significance. American Psychologist, 44, 120-126.

Hinde, R. A. (1997). Relationships: A dialectic perspective. Hove, East Sussex: Psychology Press.

Hu, L. T., \& Bentler, M. P. (1999). Cut-off criteria for fit indexes in covariance structure analysis: Conventional criteria versus new alternatives. Structural Equation Modeling, 6, 1-55.

Jöreskog, K. G. (1999). How large can a standardized coefficient be? [Online]. Retrieved from http://www.ssicentral.com/lisrel/column2.htm.

Jöreskog, K. G., \& Sörbom, D. (1996). LISREL 8: User's reference guide (2nd ed.). Chicago, IL: Scientific Software International.

Kashy, D. A., \& Kenny, D. A. (1990). Analysis of family research designs: A model of interdependence. Communication Research, 17, 462-482.

Kenny, D. A. (1994). Interpersonal perception: A social relations analysis. New York: Guilford Press.

Kenny, D. A. (2001). Measuring model fit [Online]. Retrieved [2/22/01] from http://nw3.nai.net/ dakenny/fit.htm.

Kenny, D. A., \& La Voie, L. (1984). The Social Relations Model. In L. Berkowitz (Ed.), Advances in experimental social psychology (Vol. 18, pp. 142-182). San Diego, CA: Academic Press.

Kenrick, D. T., Sadalla, E. K., Groth, G., \& Trost, M. R. (1990). Evolution, traits, and the stages of human courtship - Qualifying the parental investment model. Journal of Personality, 58, 97-116.

Kovacs, M. (1985). The Children's Depression Inventory. Psychopharmacology Bulletin, 21, 995-998.

Kovacs, M. (1992). Children's Depression Inventory manual. Los Angeles: Western Psychological Services. 
Laursen, B., \& Bukowski, W. M. (1997). A developmental guide to the organisation of close relationships. International Journal of Behavioral Development, 21, 747-770.

Lin, Y. W., \& Rusbult, C. E. (1995). Commitment to dating relationships and cross-sex friendships in America and China. Journal of Social and Personal Relationships, 12, 7-26.

Maccoby, E. E. (1992). The role of parents in the socialization of children: An historical overview. Developmental Psychology, 28, 1006-1017.

Meeus, W., Akse, J., Branje, S. J. T., Ter Bogt, T., Delsing, M. J. M. H., \& Doorn, M. (2004). [Codebook of the research project CONflicts and MAnagement of Relationships (CONAMORE). First wave: 2001]. Unpublished manuscript, Utrecht University, The Netherlands.

Reis, H. T., Collins, W. A., \& Berscheid, E. (2000). The relationship context of human behavior and development. Psychological Bulletin, 126, 844-872.

Rusbult, C. E. (1983). A longitudinal test of the investment model: The development (and deterioration) of satisfaction and commitment in heterosexual involvement. Journal of Personality and Social Psychology, 45, 101-117.

Rusbult, C. E., Johnson, D. J., \& Morrow, G. D. (1986). Predicting satisfaction and commitment in adult romantic involvements: An assessment of the generalizability of the investment model. Social Psychology Quarterly, 49, 81-89.

Rusbult, C. E., Martz, J. M., \& Agnew, C. R. (1998). The investment model scale: Measuring commitment level, satisfaction level, quality of alternatives, and investment size. Personal Relationships, 5, 357-391.

Russell, A., Pettit, G. S., \& Mize, J. (1998). Horizontal qualities in parent-child relationships: Parallels with and possible consequences for children's peer relationships. Developmental Review, 18, 313-352.

Sarason, B. R., Pierce, G. R., \& Sarason, I. G. (1990). Social support: The sense of acceptance and the role of relationships. In B. R. Sarason, I. G. Sarason, \& G. R. Pierce (Eds.), Social support: An interactional view (pp. 97-128). New York: John Wiley \& Sons.

Snijders, T. A. B., \& Kenny, D. A. (1999). The Social Relations Model for family data: A multilevel approach. Personal Relationships, 6, 471-486. 